\title{
Hazard-consistent response spectra in the Region of Murcia (Southeast Spain): comparison to earthquake-resistant provisions
}

\author{
Jorge M. Gaspar-Escribano • Belén Benito • \\ Julián García-Mayordomo
}

\begin{abstract}
Hazard-consistent ground-motion characterisations of three representative sites located in the Region of Murcia (southeast Spain) are presented. This is the area where the last three damaging events in Spain occurred and there is a significant amount of data for comparing them with seismic hazard estimates and earthquake-resistant provisions. Results of a probabilistic seismic hazard analysis are used to derive uniform hazard spectra (UHS) for the 475-year return period, on rock and soil conditions. Hazard deaggregation shows that the largest hazard contributions are due to small, local events for short-period target motions and to moderate, more distant events for long-period target motions. For each target motion and site considered, the associated specific response spectra (SRS) are obtained. It is shown that the combination of two SRS, for short- and long-period ground motions respectively, provides a good approximation to the UHS at each site. The UHS are compared to design response spectra contained in current Spanish and European seismic codes for the 475-year return period. For the three sites analysed, only the Eurocode 8 (EC8) type 2 spectrum captures the basic shape of the UHS (and not the EC8 type 1, as could be expected a priori). An alternative response spectrum, anchored at short- and long-period accelerations, is tested, providing a close match to the UHS spectra at the three sites. Results underline the important contribution of the frequent, low-to-moderate earthquakes that characterize the seismicity of this area to seismic hazard (at the 475 -year return period).
\end{abstract}

Keywords Ground-motion · Hazard deaggregation - Response spectrum - Spain . Eurocode $8 \cdot \mathrm{NCSE}-02$

\footnotetext{
J. M. Gaspar-Escribano $\quad$ B. Benito

Universidad Politécnica de Madrid, ETSI Topografía, Geodesia y Cartografía, Campus Sur UPM, Ctra. de Valencia, $\mathrm{km}$ 7.5, 28031 Madrid, Spain

e-mail: jgaspar@topografia.upm.es

J. García-Mayordomo

Laboratorio de Geotecnia, Centro de Estudios y Experimentaciones de Obras Públicas (CEDEX), c/o Alfonso XII 3-5, 28014 Madrid, Spain,
} 


\section{Introduction}

The Region of Murcia lies in an area of low-to-moderate seismicity with relatively high seismic hazard in comparison to other parts of Spain. Although felt seismic events are not rare in this region, the absence of strong earthquakes in the recent past led the population and authorities to have a low level of concern toward seismic risk (Benito and Gaspar-Escribano 2007). However, this situation changed during the last years due to the occurrence of three earthquakes in a reduced area of the Region: the 1999 Mula 2002 SW Bullas and 2005 La Paca earthquakes. Although these events had low magnitude $\left(M_{w} \leq 5.0\right)$, they produced significant alarm in the population and damage to structures, the last one reaching maximum EMS intensities of VII. Emergency services from different parts of the Region were mobilized. Dozens of traditional buildings were severely damaged-some of them were declared uninhabitable - and several families had to be relocated temporarily (Buforn et al. 2006; Benito et al. 2007).

The experience of these damaging earthquakes, the availability of new data, and a renewed interest from researchers and from local and national authorities fomented the development of seismotectonic, seismic hazard and risk assessment studies in the region (Murphy 1999; Buforn and Sanz de Galdeano 2001; Mancilla et al. 2002; Martínez-Díaz et al. 2002; GarcíaMayordomo 2005; Buforn et al. 2005; Gaspar-Escribano et al. 2005; Buforn et al. 2006; Benito et al. 2007; Gaspar-Escribano and Benito 2007; García-Mayordomo et al. 2007). In this context, Civil Protection of the Region of Murcia and the Spanish National Geographic Institute (IGN) led and financed the RISMUR Project, which is the basis for the new risk mitigation plan of the Region of Murcia (SISMIMUR Plan, DGPC 2006). The RISMUR Project involved a multidisciplinary team addressing seismic hazard, geotechnical mapping, vulnerability assessment of the Murcian building stock and damage evaluation for the expected seismic action with $10 \%$ probability of exceedance in 50 years. Finally, recommendations for future developments were provided (Benito et al. 2006b). The part of the RISMUR project dealing with hazard-consistent ground-motion characterisation constitutes the core of this paper.

Previous work on ground-motion characterisation of the Region of Murcia focused on the damaging, low-magnitude events of 1999, 2002 and 2005 (Gaspar-Escribano and Benito 2007). Based on the available ground-motion records (for epicentral distances larger than $20 \mathrm{~km}$ ) and estimates of ground-motion predictive relations for the epicentral areas, these authors concluded that short-period ground-motions could have had a significant impact on observed damage trends. However, it remains unresolved whether these ground-motions, corresponding to three earthquakes, are representative of the expected ground motions used for earthquake-resistant design of normal-importance structures (usually taken as the ground motions that are expected to be unexceeded with a $90 \%$ probability in 50 years). In particular, it will be interesting to compare these observed ground motions with the expected ground motions calculated through probabilistic seismic hazard analysis (PSHA) and with the response spectra used in earthquake-resistant design provisions.

In order to complete this data-based ground-motion characterisation with hazard-consistent response spectra, the results of a recent PSHA study carried out in the region (Benito et al. 2006a; García-Mayordomo et al. 2007) are used. Elastic, 5\%-damped uniform hazard spectra (UHS) (all spectra presented in this study are elastic and have a critical damping of 5\%) at three significant sites of the Region of Murcia are obtained. Additionally, seismic hazard is deaggregated for different target ground-motions to find the magnitude-distance-epsilon bins with maximum hazard contributions at each site (epsilon is defined as the number of standard deviations considered to compute ground motions at a given site through a ground-motion 
prediction relation). Subsequently, specific empirical response spectra (SRS) corresponding to these bins are obtained. The usefulness of these spectra in structural design is discussed in the context of current earthquake-resistant codes, as the Spanish Seismic Code NCSE-02 (NCSE-02 2002) and the Eurocode 8 (CEN 2004). Finally, it is shown that the use of a spectral shape anchored at short- and long-period spectral accelerations provides a response spectrum that closely resembles the UHS. The implementation of such a response spectrum on seismic codes is recommended.

\section{Seismic hazard at selected sites of the Region of Murcia}

The first part of the RISMUR Project consisted on the probabilistic seismic hazard assessment of the Region of Murcia and is briefly described below. Details on the RISMUR PSHA can be found elsewhere (Benito et al. 2006a; García-Mayordomo et al. 2007).

The RISMUR PSHA included a logic tree for handling epistemic uncertainties related to different ground-motion prediction relations and seismic source models. Three groundmotion relations, mainly developed from European strong motion data, were considered: Ambraseys et al. (1996) (recently updated by Ambraseys et al. 2005), Sabetta and Pugliese (1996) and Berge-Thierry et al. (2003). As these models use different variables definitions, their combination in a logic tree required making some adjustments: distances were transformed to epicentral distance and magnitudes to moment magnitude $\mathrm{M}_{\mathrm{w}}$ (e.g., Sabetta et al. 2005). Moreover, predicted accelerations were assumed equivalent to the geometrical mean of both horizontal components with less than $5 \%$ bias for all periods (e.g., Bommer et al. 2005). Three source models were adopted (Fig. 1): the model used to derive the hazard map of the Spanish Seismic Code NCSE-02, the model of López-Casado et al. (1995) and the model of García-Mayordomo (2005). They have different number of zones depending on the scale adopted and extent of the region of application. Hence, NCSE-02 is a countrywide model composed of relatively large areas, López-Casado et al. (1995) model is a lower-scale model developed for southern Spain and García-Mayordomo (2005) model is specifically derived for the Region of Murcia. All three models consider source areas of distributed seismicity. Extra source zones at the North African coast were added for considering the influence of North African seismicity on seismic hazard estimates at selected sites. Additionally, the model of García-Mayordomo (2005) includes faults as seismic sources. For area sources a doubly-bounded Gutenberg-Richter recurrence model was adopted. Maximum magnitudes, b-values and annual rates of the different zones are listed in Table 1. For fault sources, a characteristic model of earthquake occurrence was used. Recurrence periods and maximum magnitudes are given in Table 2.

The logic tree used, including the corresponding weights, is presented in Fig. 2. A higher weight was assigned to the source model specifically developed for the Region of Murcia. The ground-motion relation of Sabetta and Pugliese (1996) was assigned a lower weight for a number of reasons: it predicts spectral velocities (instead of spectral accelerations), and it is developed exclusively with Italian data, and consequently, its extrapolation to other areas seems less adequate than for the other relations, derived from data of a broader area that includes the western Mediterranean. Assigning a lower weight to the model of Sabetta and Pugliese (1996) is consistent with the conclusions of Douglas et al. (2006), who based on the results of an application of the composite model approach for southern Spain, found that the model of Sabetta and Pugliese (1996) adapted for the target area contained larger epistemic uncertainty than the models of Ambraseys et al. (1996) and of Berge-Thierry et al. (2003). 
(a)

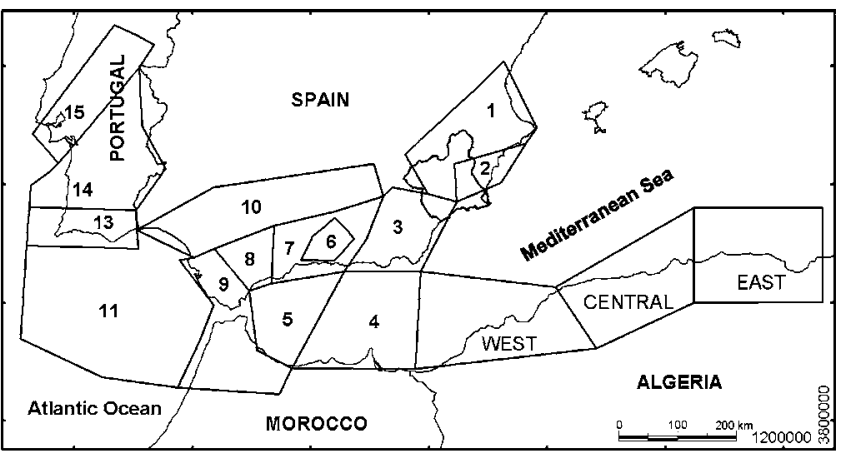

(b)

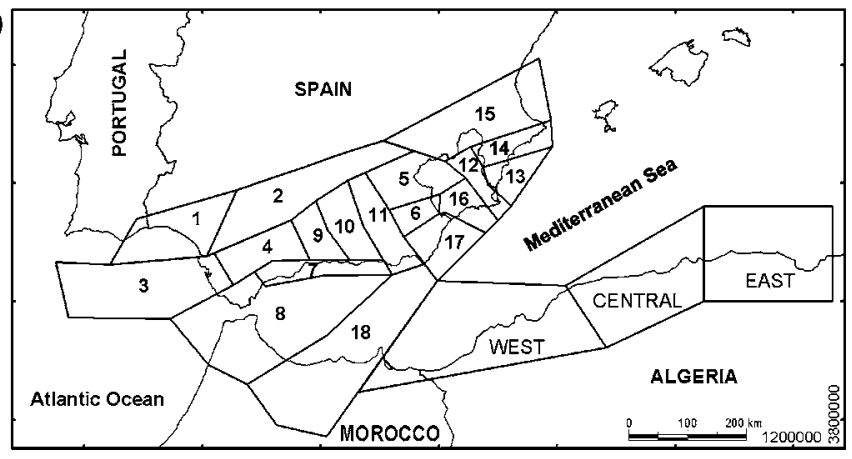

(c)

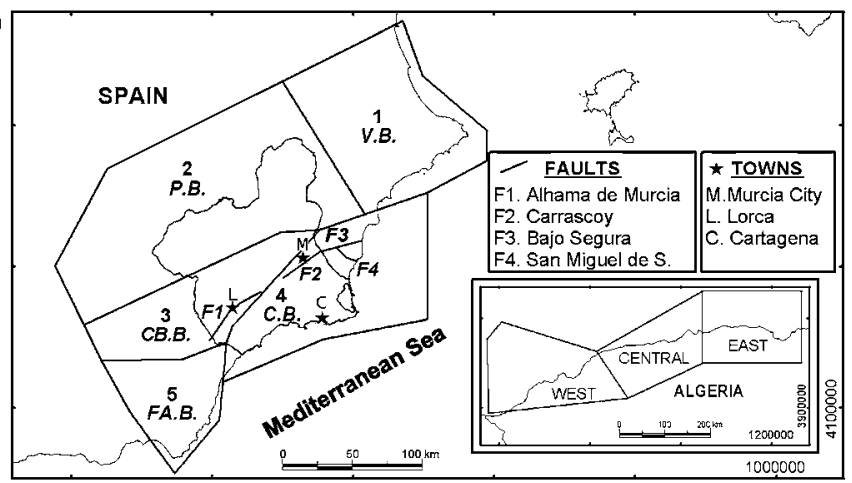

Fig. 1 Seismic source models used in the RISMUR PSHA. (a) Zonification used to derive the NCSE-02 hazard map; (b) López-Casado et al. (1995); (c) García-Mayordomo (2005). All models are complemented with additional source areas along the North African coast (E.A.: East African; C.A.: Central African; W.A.: West African zones)

Seismic hazard was calculated for a regular grid covering the entire Region. Maps of horizontal geometrical mean of expected peak ground accelerations ( $\mathrm{PGA}_{475}$ ) and spectral accelerations $\left(\mathrm{SA}_{475}(\mathrm{~T})\right)$ for the 475 -year return period and rock conditions show that hazard is higher along a SE-NW-trending strip that crosses the Region. Maximum expected ground motions are obtained for short vibration periods (around $0.1-0.2 \mathrm{~s}$ ) and range between 180 and $320 \mathrm{~cm} / \mathrm{s}^{2}$. Long-period $(1.0 \mathrm{~s})$ spectral accelerations range between 45 and $75 \mathrm{~cm} / \mathrm{s}^{2}$. As an example of the hazard maps obtained, the estimated PGA 475 map is shown in Fig. 3. 
Table 1 Seismic parameters for the three source models considered in the RISMUR PSHA $\left(\lambda_{0}\right.$ is the earthquake occurrence frequency at threshold magnitude; $\beta$ is the slope of the Gutenberg-Richter curve and $\mathrm{M}_{\max }$ the maximum expected magnitude)

\begin{tabular}{|c|c|c|c|c|c|c|c|c|c|c|c|}
\hline \multicolumn{4}{|c|}{ NCSE-02 } & \multicolumn{4}{|c|}{ López-Casado et al. (1995) } & \multicolumn{4}{|c|}{ García-Mayordomo (2005) } \\
\hline Zone & $\lambda_{0}$ & $\beta$ & $\mathbf{M}_{\max }$ & Zone & $\lambda_{0}$ & $\beta$ & $\mathrm{M}_{\max }$ & Zone & $\lambda_{0}$ & $\beta$ & $\mathrm{M}_{\max }$ \\
\hline 1 & 0.713 & 2.167 & 6.8 & 1 & 0.264 & 2.208 & 6.4 & 1 & 0.373 & 2.395 & 6.2 \\
\hline 2 & 0.756 & 2.227 & 6.8 & 2 & 0.201 & 1.852 & 7.2 & 2 & 0.337 & 1.913 & 7.0 \\
\hline 3 & 0.730 & 1.978 & 6.8 & 3 & 0.246 & 1.702 & 7.2 & 3 & 0.487 & 2.220 & 6.2 \\
\hline 4 & 0.800 & 2.107 & 7.0 & 4 & 0.242 & 1.877 & 7.1 & 4 & 0.479 & 2.121 & 6.2 \\
\hline 5 & 0.201 & 2.745 & 6.0 & 5 & 0.177 & 1.875 & 6.2 & 5 & 0.216 & 2.178 & 6.4 \\
\hline 6 & 0.601 & 2.040 & 6.9 & 6 & 0.191 & 2.047 & 6.2 & E. A. & 2.494 & 2.551 & 7.5 \\
\hline 7 & 0.245 & 2.017 & 7.1 & 7 & 0.143 & 1.759 & 7.0 & C. A. & 4.348 & 2.019 & 8.0 \\
\hline 8 & 0.230 & 2.056 & 5.8 & 8 & 0.356 & 2.003 & 7.0 & W.A. & 1.221 & 1.796 & 6.9 \\
\hline 9 & 0.183 & 1.996 & 6.6 & 9 & 0.268 & 1.953 & 6.9 & & & & \\
\hline 10 & 0.238 & 1.897 & 7.2 & 10 & 0.585 & 2.183 & 6.9 & & & & \\
\hline 11 & 0.426 & 1.934 & 7.2 & 11 & 0.264 & 1.886 & 6.8 & & & & \\
\hline 13 & 0.182 & 2.618 & 5.5 & 12 & 0.365 & 2.455 & 6.8 & & & & \\
\hline 14 & 0.313 & 1.766 & 5.9 & 13 & 0.319 & 1.955 & 6.8 & & & & \\
\hline 15 & 0.470 & 2.003 & 6.9 & 14 & 0.297 & 2.812 & 6.8 & & & & \\
\hline E. A. & 2.981 & 2.171 & 7.5 & 15 & 0.354 & 1.923 & 6.8 & & & & \\
\hline C. A. & 4.350 & 2.019 & 8.0 & 16 & 0.136 & 2.141 & 6.8 & & & & \\
\hline \multirow[t]{5}{*}{ W.A. } & 1.160 & 1.775 & 6.9 & 17 & 0.299 & 2.375 & 6.4 & & & & \\
\hline & & & & 18 & 0.962 & 2.383 & 6.8 & & & & \\
\hline & & & & E. A. & 2.981 & 2.171 & 7.5 & & & & \\
\hline & & & & C. A. & 4.348 & 2.019 & 8.0 & & & & \\
\hline & & & & W.A. & 1.458 & 1.943 & 6.9 & & & & \\
\hline
\end{tabular}

Fault-source parameters (García-Mayordomo 2005 model) are given in Table 2

Table 2 Maximum expected magnitudes $\left(\mathrm{Mw}_{\max }\right.$ ) and mean recurrence periods (MRP) for seismogenetic fault segments defined in the model of García-Mayordomo (2005)

\begin{tabular}{llll}
\hline Fault & Segment & Mw & MRP (years) \\
\hline Alhama de Murcia & Puerto Lumbreras-Lorca & 6.8 & 7000 \\
& Lorca-Totana & 6.7 & 2000 \\
Carrascoy & & 6.8 & 6000 \\
San Miguel de Salinas & & 6.5 & 8000 \\
Bajo Segura & Hurchillo & 6.3 & 1700 \\
& Benejúzar & 6.2 & 2000 \\
& Guardamar & 6.1 & 3000 \\
\hline
\end{tabular}

In the subsequent stage, site amplification factors were defined and a suite of hazard maps on soil conditions for different spectral ordinates and return periods was produced. The geotechnical classification of the Region of Murcia carried out in the RISMUR Project by Tsige and García Flórez (2006), which distinguishes among sites with different response to seismic shaking, was used to introduce local amplification effects (Benito et al. 2006b). Due to the large-scale approach used, it was unviable to perform site-specific analyses for assessing ground amplification factors, and these were obtained by averaging amplification factors proposed in the literature. Specifically, amplification factors for PGA (Table 3) were derived by taking the arithmetic mean of the PGA amplification factors provided in different codes: the 2003 National Earthquake Hazard Reduction Program (NEHRP) Provisions (BSSC 2003), the Eurocode 8 (CEN 2004) and the NCSE-02 (2002). In order to take into 


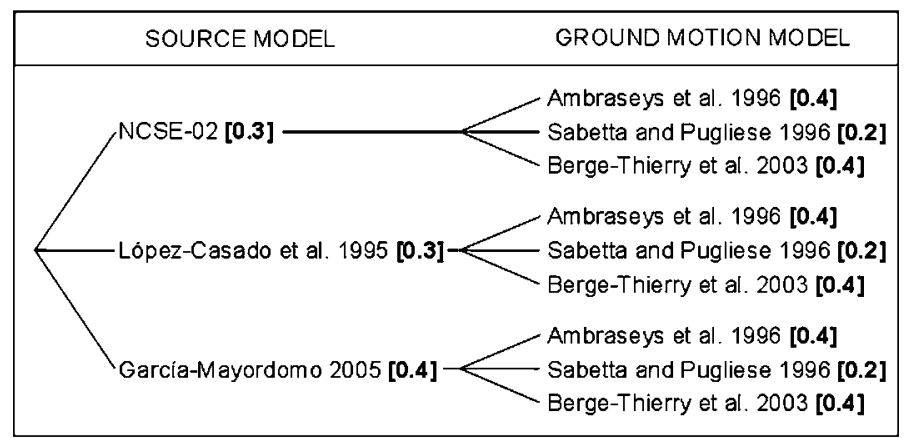

Fig. 2 Logic tree used in the RISMUR PSHA indicating the weights assigned to the different branches (in brackets)

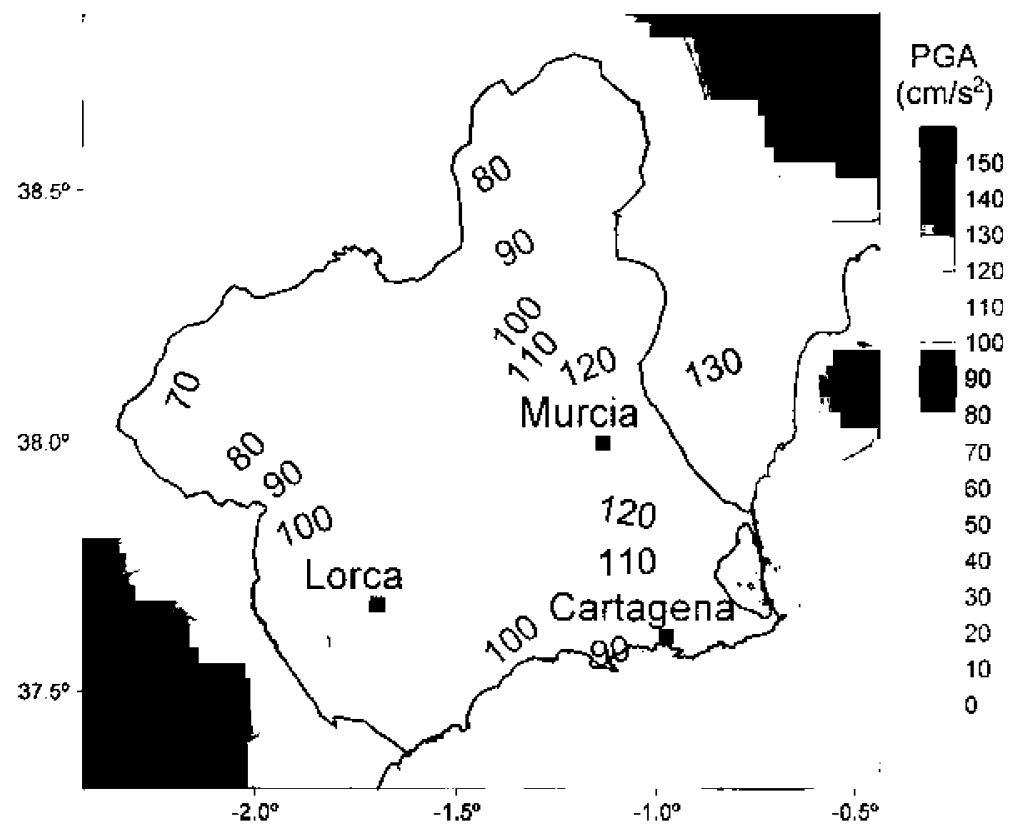

Fig. 3 Map of expected peak ground acceleration (in $\mathrm{cm} / \mathrm{s}^{2}$ ) on rock conditions for a return period of 475 years

account the non-linearity and period-dependency of soil response, amplification factors for spectral accelerations (Table 3) were adapted from the 2003 NEHRP Provisions (Dobry et al. 2000). As the averaged PGA amplification factor calculated above does not correspond to the PGA amplification factor contained in the 2003 NEHRP Provisions, it was necessary to recalculate amplification factors for the short-period range (from 0.0 through $0.1 \mathrm{~s}$ ). This was done by linear interpolation between the averaged amplification factor for PGA and the NEHRP amplification factor for $\mathrm{SA}(0.1 \mathrm{~s})$.

Maximum expected ground motions including the corresponding soil amplification for the 475-year return period are found along main river valleys (e. g., Segura and Guadalentín 
Table 3 Ground amplification factors defined in the RISMUR Project (Benito et al. 2006b)

\begin{tabular}{|c|c|c|c|c|c|c|c|c|}
\hline \multirow[t]{2}{*}{ Soil class } & \multirow[t]{2}{*}{ PGA } & \multicolumn{2}{|c|}{$\mathrm{SA}(0.1 \mathrm{~s})$} & \multicolumn{2}{|c|}{$\mathrm{SA}(0.2 \mathrm{~s})$} & \multicolumn{2}{|c|}{$\mathrm{SA}(0.5 \mathrm{~s})$} & \multirow[t]{2}{*}{$\mathrm{SA}(1.0 \mathrm{~s})$} \\
\hline & & $\leq 0.1 \mathrm{~g}$ & $>0.1 \mathrm{~g}$ & $\leq 0.1 \mathrm{~g}$ & $>0.1 \mathrm{~g}$ & $\leq 0.1 \mathrm{~g}$ & $>0.1 \mathrm{~g}$ & \\
\hline A & 0.8 & 0.8 & 0.8 & 0.8 & 0.8 & 0.8 & 0.8 & 0.8 \\
\hline B & 1.0 & 1.0 & 1.0 & 1.0 & 1.0 & 1.0 & 1.0 & 1.0 \\
\hline $\mathrm{C}$ & 1.2 & 1.2 & 1.2 & 1.2 & 1.2 & 1.4 & 1.4 & 1.7 \\
\hline $\mathrm{D}$ & 1.4 & 1.6 & 1.6 & 1.6 & 1.6 & 1.9 & 1.8 & 2.4 \\
\hline $\mathrm{E}$ & 1.8 & 2.5 & 1.5 & 2.5 & 1.5 & 2.9 & 2.8 & 3.5 \\
\hline $\mathrm{F}$ & $2.0 *$ & $2.5^{*}$ & $2.2^{*}$ & $2.5 *$ & $2.2 *$ & $2.9 *$ & $2.8 *$ & $3.5^{*}$ \\
\hline
\end{tabular}

For the periods not shown in the table, the amplification factors are derived by linear interpolation, being constant above $1.0 \mathrm{~s}$. Different factors are applied depending on the ground-motion amplitude. Asterisks mean that site-specific investigations are required to better constrain amplification factors
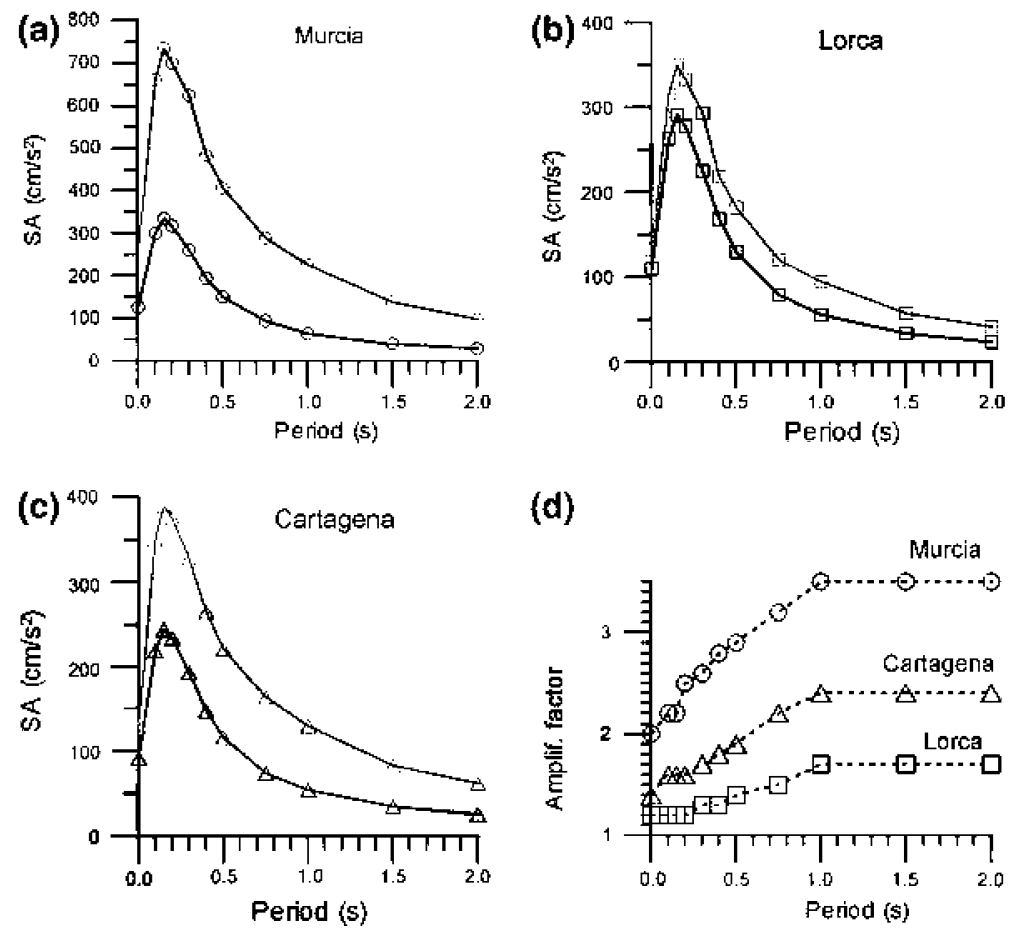

Soil UHS Rock UHS

Fig. 4 Uniform hazard response spectra at: (a) Murcia City, (b) Lorca and (c) Cartagena for rock conditions (black lines) and soil conditions (gray lines). (d) Soil amplification factors (consistent with values of Table 3)

rivers, including Murcia City) and coastal plains (e. g., Mar Menor), with $\mathrm{PGA}_{475}>$ $250 \mathrm{~cm} / \mathrm{s}^{2}, \mathrm{SA}_{475}(0.2 \mathrm{~s})>750 \mathrm{~cm} / \mathrm{s}^{2}$ and $\mathrm{SA}_{475}(1.0 \mathrm{~s})>250 \mathrm{~cm} / \mathrm{s}^{2}$.

This work focuses on three of the most important cities of the Region: the city of Murcia, Lorca and Cartagena. Mean uniform hazard spectra at these cities for the 475-year return period on rock and soil conditions (rock and soil UHS) are shown in Fig. 4. Note that the response spectra for the three sites present maximum spectral accelerations in the shortperiod range $(0.1-0.2 \mathrm{~s})$. These sites are primarily characterized by very soft, hard and soft 
soil sites, respectively (Benito et al. 2006b). The correspondence to soil categories defined in different earthquake-resistant provisions is given in Table 4. Finally, mean uniform hazard spectra for soil conditions (soil UHS) are obtained by multiplying the respective rock UHS by the amplification factor for each site (Fig. 4d).

\section{Hazard deaggregation}

Seismic hazard estimates for different target motions is deaggregated into partial contributions of magnitude-distance-epsilon $(\mathrm{M}-\mathrm{D}-\varepsilon$ ) bins in order to identify the controlling earthquakes, defined by those $\mathrm{M}-\mathrm{D}-\varepsilon$ bins with larger contribution to the total seismic hazard at those target motions (Bazzurro and Cornell 1999).

Different target motions corresponding to the PSHA estimates for the 475-year return period at generic rock sites in Murcia, Lorca and Cartagena are considered (Table 5).

Table 4 Equivalence between prevailing soil class at Murcia, Lorca and Cartagena and soil categories defined in the RISMUR project and in the (model) codes used in this study

\begin{tabular}{llllll}
\hline Site & Soil & RISMUR & NCSE-02 & EC8 & NEHRP-2003 \\
\hline Murcia* & Very soft & F & IV & D & F \\
Lorca & Hard & C & II & B & C \\
Cartagena & Soft & D & III & C & D \\
\hline
\end{tabular}

*For Murcia City, NEHRP-2003 soil class E coefficients are assigned

Table 5 Target ground motions on rock condition $\mathrm{PGA}_{475}, \mathrm{SA}_{475}(0.2 \mathrm{~s}), \mathrm{SA}_{475}(0.5 \mathrm{~s})$ and $\mathrm{SA}_{475}(1.0 \mathrm{~s}) \mathrm{used}$ for hazard deaggregation at Murcia City, Lorca and Cartagena

\begin{tabular}{llllllllll}
\hline Target motion & {$\left[\mathrm{cm} / \mathrm{s}^{2}\right]$} & $\Delta \mathrm{M}_{1}$ & $\begin{array}{c}\Delta \mathrm{D}_{1} \\
{[\mathrm{~km}]}\end{array}$ & $\Delta \varepsilon_{1}$ & $\Delta \mathrm{M}_{2}$ & $\begin{array}{c}\Delta \mathrm{D}_{2} \\
{[\mathrm{~km}]}\end{array}$ & $\Delta \varepsilon_{2}$ & $\mathrm{M}^{*}$ & $\mathrm{D}^{*}$
\end{tabular}

MURCIA

$\begin{array}{lrllllllllr}\text { PGA } & 127 & (4.5-5.0) & (0-10) & (1.0-1.5) & & & & 4.9 & 8 & 1.1 \\ \text { SA }(0.2 \mathrm{~s}) & 318 & (4.5-5.0) & (0-10) & (1.0-1.5) & (5.0-5.5) & (0-10) & (0.5-1.0) & 5.2 & 10 & 0.9 \\ \text { SA }(0.5 \mathrm{~s}) & 151 & (4.5-5.0) & (0-10) & (1.5-2.0) & (5.0-5.5) & (0-10) & (0.5-1.0) & 5.4 & 9 & 0.6 \\ \text { SA }(1.0 \mathrm{~s}) & 69 & (5.5-6.0) & (10-20) & (1.0-1.5) & & & & 5.5 & 16 & 1.2\end{array}$

LORCA

\begin{tabular}{|c|c|c|c|c|c|c|c|c|c|c|}
\hline PGA & 111 & $(4.0-4.5)$ & $(0-10)$ & $(1.5-2.0)$ & & & & 4.3 & 9 & 2.0 \\
\hline $\mathrm{SA}(0.2 \mathrm{~s})$ & 278 & $(4.5-5.0)$ & $(0-10)$ & $(1.0-1.5)$ & & & & 4.7 & 8 & 1.2 \\
\hline $\mathrm{SA}(0.5 \mathrm{~s})$ & 130 & $(5.0-5.5)$ & $(0-10)$ & $(0.5-1.0)$ & $(4.5-5.0)$ & $(0-10)$ & $(1.5-2.0)$ & 5.1 & 6 & 0.6 \\
\hline $\mathrm{SA}(1.0 \mathrm{~s})$ & 62 & $(5.0-5.5)$ & $(0-10)$ & $(1.0-1.5)$ & $(5.5-6.0)$ & $(10-20)$ & $(1.0-1.5)$ & 5.5 & 20 & 1.2 \\
\hline
\end{tabular}

CARTAGENA

\begin{tabular}{lrlllllllll} 
PGA & 92 & $(4.5-5.0)$ & $(0-10)$ & $(0.5-1.0)$ & $(4.5-5.0)$ & $(0-10)$ & $(1.5-2.0)$ & 4.6 & 7 & 0.9 \\
SA(0.2 s) & 235 & $(4.0-4.5)$ & $(0-10)$ & $(1.5-2.0)$ & & & & 4.4 & 9 & 1.5 \\
SA $(0.5 \mathrm{~s})$ & 116 & $(5.5-6.0)$ & $(20-30)$ & $(1.0-1.5)$ & & & & 5.6 & 28 & 1.2 \\
$\mathrm{SA}(1.0 \mathrm{~s})$ & 59 & $(6.0-6.5)$ & $(30-40)$ & $(0.5-1.0)$ & & & & 6.0 & 32 & 0.7 \\
\hline
\end{tabular}

Magnitude-distance-epsilon bins with highest and second highest hazard contributions are labelled as $\Delta \mathrm{M}_{1}-\Delta \mathrm{D}_{1}-\Delta \varepsilon_{1}$ and $\Delta \mathrm{M}_{2}-\Delta \mathrm{D}_{2}-\Delta \varepsilon_{2}$. The second is only included when its probability density is at least $90 \%$ of $\mathrm{dM}_{1}-\mathrm{dD}_{1}-\mathrm{d} \varepsilon_{1}$ 's. $\mathrm{M}^{*}, \mathrm{D}^{*}$ and $\varepsilon^{*}$ stand for magnitude, distance and epsilon values used to calculate specific response spectra 
Specifically, four ground-motion parameters are used: the peak ground acceleration $\left(\mathrm{PGA}_{475}\right)$ and the spectral accelerations, $\mathrm{SA}_{475}(0.2 \mathrm{~s}), \mathrm{SA}_{475}(0.5 \mathrm{~s})$ and $\mathrm{SA}_{475}(1.0 \mathrm{~s})$, representative of short-, intermediate- and long-period ground-motions, respectively. Subsequently, hazard is deaggreagated in contributions of magnitude-distance-epsilon bins of width $\Delta \mathrm{M}=0.5, \Delta \mathrm{D}=10 \mathrm{~km}$ and $\Delta \varepsilon=0.5$.

For each target motion and site, bins with highest hazard contributions are listed in Table 5. In some cases, the probability density of the bin with the largest contribution does not differ notably from the contributions of other bins. This is the case for $\mathrm{SA}_{475}(0.2 \mathrm{~s})$ and $\mathrm{SA}_{475}(0.5 \mathrm{~s})$ deaggregations at Murcia, for $\mathrm{SA}_{475}(0.5 \mathrm{~s})$ and $\mathrm{SA}_{475}(1.0 \mathrm{~s})$ deaggregations at Lorca and for $\mathrm{PGA}_{45}$ deaggregation at Murcia, where the bins with the highest and the second highest hazard contribution (respectively labelled as $M_{1}-D_{1}-\varepsilon_{1}$ and $M_{2}-D_{2}-\varepsilon_{2}$ in Table 5) differ by less than $10 \%$. For this reason, the term "M-D- $\varepsilon$ bins with the largest hazard contribution" is used instead of "controlling earthquake".

Deaggregation results indicate that at the 475 -year return period the maximum hazard contribution to short-period target motions for the three sites comes from local sources (located in the immediate $10 \mathrm{~km}$ from the respective sites) and low-to-moderate magnitudes (from 4.0 to 5.5). For longer-period target motions, there is a drift of the maximum magnitudedistance-epsilon bins towards longer distances and larger magnitudes, as would be expected. No trend between epsilon and vibration period is apparent (Table 5).

For each target motion, Table 5 also contains a triplet of magnitude, distance and epsilon values labelled as $\mathrm{M}^{*}, \mathrm{D}^{*}$ and $\varepsilon^{*}$, which pertain to a $\mathrm{M}-\mathrm{D}-\varepsilon$ bin with highest hazard contribution. These are the values that give the ground-motion estimate that most closely reproduces the respective target motion when they are substituted in the ground-motion models used for the direct PSHA calculations.

\section{Specific response spectra}

The response spectra obtained by substituting the $\mathbf{M}^{*}, \mathrm{D}^{*} \varepsilon^{*}$ values in the empirical groundmotion models used in the direct hazard calculations are hereafter referred to as specific response spectra (SRS). SRS for $\mathrm{SA}_{475}(\mathrm{~T})$ target motions are useful because they provide a first approximation to hazard-consistent design spectra for structures that are regulated by the 475-year return period.

Rock SRS are presented in Fig. 5, together with soil SRS, which are obtained by multiplying rock SRS by the respective soil amplification factors (Table 3, Fig. 4d). Each plot on Fig. 5 contains five response spectra: the UHS and four SRS (for $\mathbf{M}^{*}, \mathrm{D}^{*}$ and $\varepsilon^{*}$ values with the largest contribution to $\mathrm{PGA}_{475}, \mathrm{SA}_{475}(0.2 \mathrm{~s}), \mathrm{SA}_{475}(0.5 \mathrm{~s})$ and $\mathrm{SA}_{475}(1.0 \mathrm{~s})$ target motions, respectively). As expected, the UHS is very similar to each SRS around the period of the target motion linked to the respective SRS.

SRS for $\mathrm{PGA}_{475}$ and $\mathrm{SA}_{475}(0.2 \mathrm{~s})$ are very similar for all periods and sites. They are both also similar to UHS for short periods only, lying clearly below the UHS for periods above $0.4 \mathrm{~s}$. At the same time, SRS for $\mathrm{SA}_{475}(1.0 \mathrm{~s})$ at all sites are very similar to UHS for periods above $0.4 \mathrm{~s}$. Finally, SRS for $\mathrm{SA}_{475}(0.5 \mathrm{~s})$ provide a rough approximation to UHS in the entire period domain.

Considering the good adjustment to UHS provided by the SRS for $\operatorname{SA}_{475}(0.2 \mathrm{~s})$ in the short-period range (below $0.3 \mathrm{~s}$ ) and by the SRS for $\mathrm{SA}_{475}(1.0 \mathrm{~s})$ in the intermediate-longperiod range (above $0.3 \mathrm{~s}$ ) for all sites, it is concluded that a SRS-envelope, composed by merging the first SRS from $0.0 \mathrm{~s}$ through $0.3 \mathrm{~s}$ and the second SRS above $0.3 \mathrm{~s}$ constitutes a good approximation to the 475-year UHS at representative sites of the Region of 

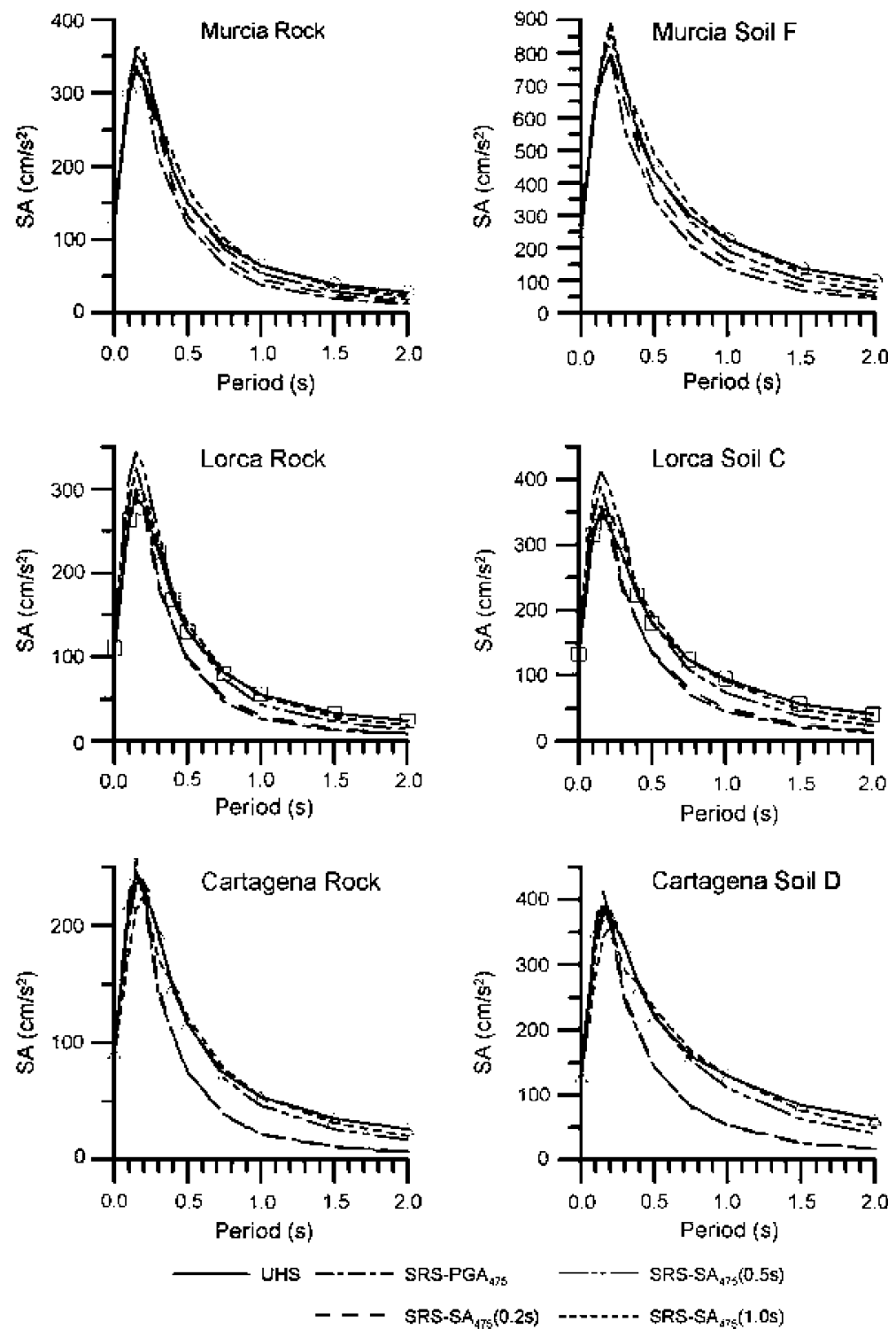

Fig. 5 UHS and SRS for $\mathrm{PGA}_{475}, \mathrm{SA}_{475}(0.2 \mathrm{~s}), \mathrm{SA}_{475}(0.5 \mathrm{~s})$ and $\mathrm{SA}_{475}(1.0 \mathrm{~s})$ target motions at Murcia City (top), Lorca (middle) and Cartagena (bottom) for rock conditions (left panels) and soil conditions (right panels)

Murcia. Consequently, UHS and SRS-envelopes can be regarded as equivalent hazard-consistent ground-motion characterisations for the sites analysed, adequate for representing the expected seismic action for a 475 -year return period.

\section{Implications for seismic hazard in Southeast Spain}

Unfortunately, there are no strong ground-motion records available matching the magnitude-distance-epsilon bins with highest hazard contribution for checking whether the SRS 
plotted in Fig. 5 are consistent with actual data or not. The ground-motion data available correspond to small events $\left(\mathbf{M}_{\mathrm{w}} \leq 5.0\right)$ and epicentral distances above $20 \mathrm{~km}$. In general, the recorded response spectra present maximum spectral accelerations in the same period range as the corresponding SRS obtained in the present study (between 0.1 and $0.4 \mathrm{~s}$ ), but lower amplitudes (of about $100 \mathrm{~cm} / \mathrm{s}^{2}$, Gaspar-Escribano and Benito 2007). Hence, although the absolute accelerations are necessarily low due to the long epicentral distances, the available data show that maximum amplitudes are recorded precisely in the same period range where UHS and SRS envelopes reach the largest SA values in our study.

The significance of the hazard-consistent response spectra derived above must be referred to the seismotectonic framework of the region. Previous work indicated that the seismicity of the Region of Murcia is characterized by relatively frequent, moderate-magnitude (M 5.0) earthquakes (Buforn et al. 2005; Benito et al. 2007). Precisely, these frequent earthquakes can be associated to magnitudes and distances with maximum hazard contribution deduced for short-period target motions at Murcia City, Lorca and Cartagena (Table 5). Given the absence of local instrumental data, the SRS response spectra presented in Fig. 5 may be used for characterizing ground motion related to these frequent earthquakes in a first-order approach.

Thus, results of the present analysis confer an important hazard contribution to low-tomoderate-magnitude and short-distance events. The corresponding ground motions are used to test the performance of current earthquake-resistant provisions.

\section{Comparison to seismic codes}

According to the Spanish Seismic Code NCSE-02, normal-importance buildings, such as conventional dwellings, must be designed for return period of 500 years. This is very similar to the 475-year return period used in this study and in most European seismic codes (García-Mayordomo et al. 2004), and it is recommended in Eurocode 8 for non-collapse limit state. Thus, it is worthwhile comparing the NCSE-02 and Eurocode 8 response spectra with the hazard-consistent response spectra presented in this paper at each location to investigate whether they are mutually consistent or present discrepancies.

\subsection{Spanish seismic code NCSE-02}

The NCSE-02 response spectrum is based on a spectral shape scaled with the so-called basic acceleration $\mathrm{a}_{\mathrm{b}}$ and includes factors that account for soil amplification, building importance and the contribution of the distant Azores-Gibraltar seismic source (NCSE-02 2002). The basic acceleration is in practice associated to maximum surface horizontal peak ground acceleration and its value is extracted from the NCSE-02 hazard map. Amplification factors are basically defined by the mean shear-wave velocity of the uppermost $30 \mathrm{~m}$-thick soil layer and they are applied to the $a_{b}$ value. For the Murcia Region, the contribution of the distant Azores-Gibraltar seismic zone is null.

The comparison between UHS and NCSE-02 response spectrum at each location is shown in Fig. 6. In addition, another spectrum similar to the NCSE-02 spectra but scaled with the $\mathrm{PGA}_{475}$ value derived in the RISMUR PSHA is plotted. Differences between $\mathrm{a}_{\mathbf{b}}$ and PGA 45 for the same site are reflected in the response spectrum. Thus, in Murcia City and Lorca, where both values are similar, the corresponding absolute response spectra do not present substantial differences. In contrast, in Cartagena, where $a_{b}$ is about $40 \%$ lower than PGA 475 , the NCSE-02 response spectrum scaled with $a_{b}$ gives significantly lower ground motions than the response spectrum scaled with PGA $_{475}$. This illustrates the dramatic effect of the 

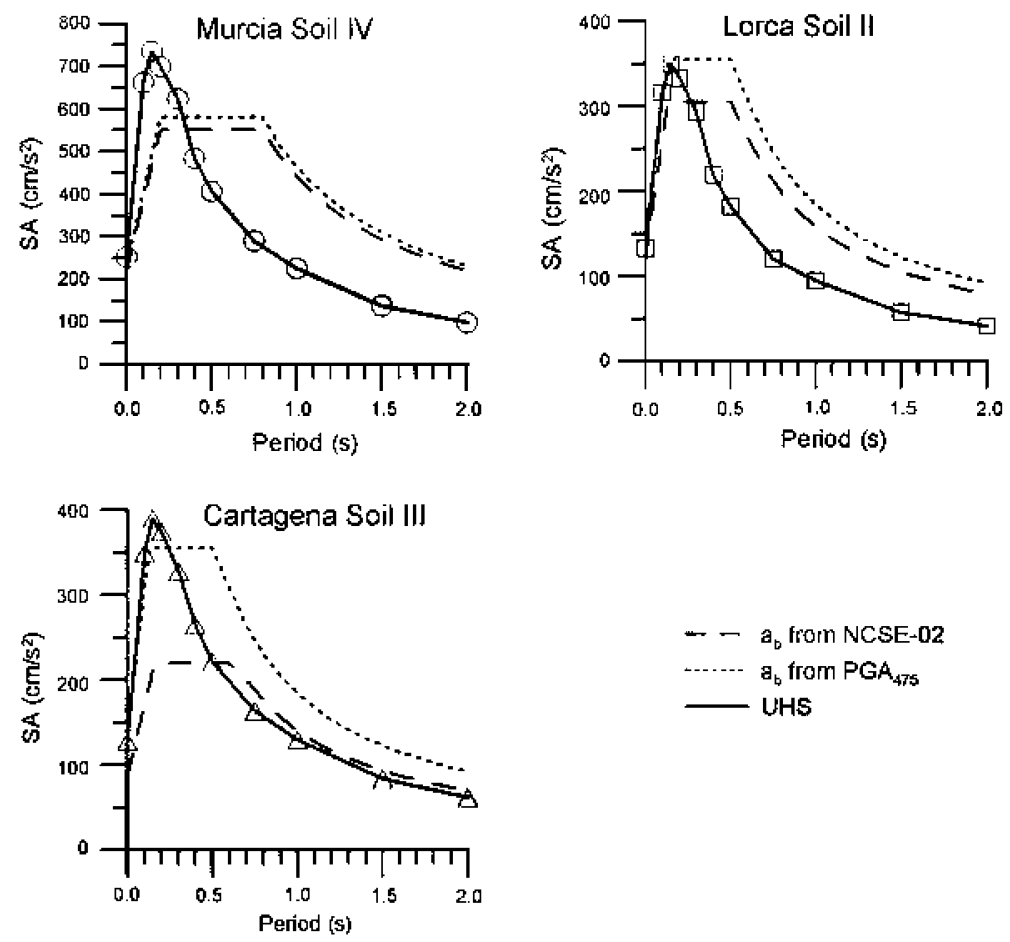

Fig. 6 UHS and NCSE-02 response spectra at Murcia City, Lorca and Cartagena for soil conditions. Two $a_{b}$ values are used at each site

underestimation of the single acceleration value used for scaling the NCSE-02 response spectrum (as compared with the PGA value obtained in the RISMUR PSHA), which may lead to a misestimation of design ground-motions for all periods.

For all the sites studied, the UHS generally gives higher ground-motion estimates for short periods (below 0.3-0.5 s, depending on the site) than the NCSE-02 spectra, and conversely, the UHS gives lower ground-motion estimates than the NCSE-02 spectra for long periods. A similar effect was found by Gaspar-Escribano and Benito (2007) for normalised spectral shapes of ground-motion records available in the region (magnitudes below 5 and distances above $20 \mathrm{~km}$ ) and for some simulated scenarios reproducing the conditions at the most damaged towns after the 1999, 2002 and 2005 earthquakes. This is an important issue because the majority of buildings in the Region of Murcia have one to two stories and their fundamental periods of vibration are likely to be very short (of the order of $0.1-0.2 \mathrm{~s}$ ), and therefore, they are most vulnerable to short-period ground motions caused by these frequent, moderate-magnitude earthquakes (Gaspar-Escribano et al. 2005).

\subsection{Eurocode 8}

The Eurocode 8 (EC8) response spectrum presents some similarities to the NCSE-02 response spectrum. Both are scaled with an acceleration value at zero period (in EC8 it is called $\mathrm{a}_{\mathrm{gR}}$, a PGA value on rock condition that must be provided by national agencies); both include building-importance coefficients, and both present constant soil amplification factors for the full range of response periods. Dissimilarities concern definitions of reference periods 
separating parts of the spectrum, the absence of a strong-decay curve for very long periods in NCSE-02, the absence of distant-source contribution factors in EC8, and the distinction between two types of spectral shapes in EC8 depending on the magnitude of hazard-controlling earthquakes in the area of application. EC8 type 1 response spectrum is recommended for seismic areas where the $M_{s}$ magnitude of such earthquakes exceeds 5.5 (typically very active regions of southern Europe, such as Greece or Italy) and EC8 type 2 otherwise (typically for stable areas of central and northern Europe, such as Germany or Finland). Note that EC8 does not make any specific reference to the period of vibration of target motions, rendering this definition somewhat ambiguous because controlling earthquakes at a given site may correspond to very distinct magnitude events depending on the period of vibration of the target ground-motion considered. Nevertheless, as the EC8 spectra are constrained by peak ground accelerations, it appears to be more internally consistent to use the spectrum type corresponding to the magnitude of the controlling earthquake at very low-period target ground motions (or directly, $\mathrm{PGA}_{475}$ ).

Figure 7 shows the comparison between the EC8 response spectra (both types) and the UHS obtained in this study at each location. Again two $\mathrm{a}_{\mathrm{gR}}$ values are considered, one derived from the NCSE-02 hazard map and another one coinciding with PGA475. For all sites, EC8 type 2 spectra capture the shape of the corresponding UHS fairly well. By contrast, EC8 type 1 spectra provide too high and too low ground motions for long and short periods, respectively, as compared to UHS. Again, the strong effect of the $\mathrm{a}_{\mathrm{gR}}$ value considered at Cartagena on EC8 response spectra is observed. The better match of the UHS with EC8 type 2 spectrum is consistent with the fact that the earthquakes that most contribute to hazard in our study (PGA475target motion) have magnitudes lower than 5.5.

\section{Discussion}

Hazard-consistent ground-motion characterisations of an area limited by the scant availability of strong-motion data, the Region of Murcia, are presented in this paper. Using ground-motion records from three earthquake sequences recently occurred in this area $\left(\mathrm{M}_{\mathrm{W}}\right.$ magnitudes up to 5.0) and modelling different scenarios at damaged locations, GasparEscribano and Benito (2007) pointed out the incidence on damage trends of factors such as the prevalence of relatively soft soils, relatively high spectral accelerations in the shortperiod domain and the number of stories of common buildings.

Results of the present study indicate that such low-magnitude events have a significant hazard contribution for 475-year short-period target motions at sites located in the immediate vicinity of the epicenter. Thus, ground-motions related to these earthquakes should be thoroughly accounted for in design of structures regulated by the 475-year return period. Until more data are collected and better-constrained ground-motion models are composed, the empirical response spectra presented in this work may be used for this purpose.

Hazard-consistent response spectra (UHS and SRS-envelopes derived in this study) and response spectra of current earthquake-resistant codes (NCSE-02 and EC8 types 1 and 2) show dissimilarities for different spectral domains. The approach used to construct response spectra in both codes is based on two inputs: a zero-period acceleration value and a spectral shape. Hence, an over- or under-estimation of the first (as in Cartagena, see Figs. 6 and 7) and/or an unconstrained definition of the second may lead to unrealistic hazard-consistent response spectra (Pousse et al. 2005; Bommer and Pinho 2006; Gaspar-Escribano and Benito 2007). This limitation is stronger in the NCSE-02 code, since the implementation of two spectral shapes in Eurocode 8 allows better constraint of the final spectrum. However, this 

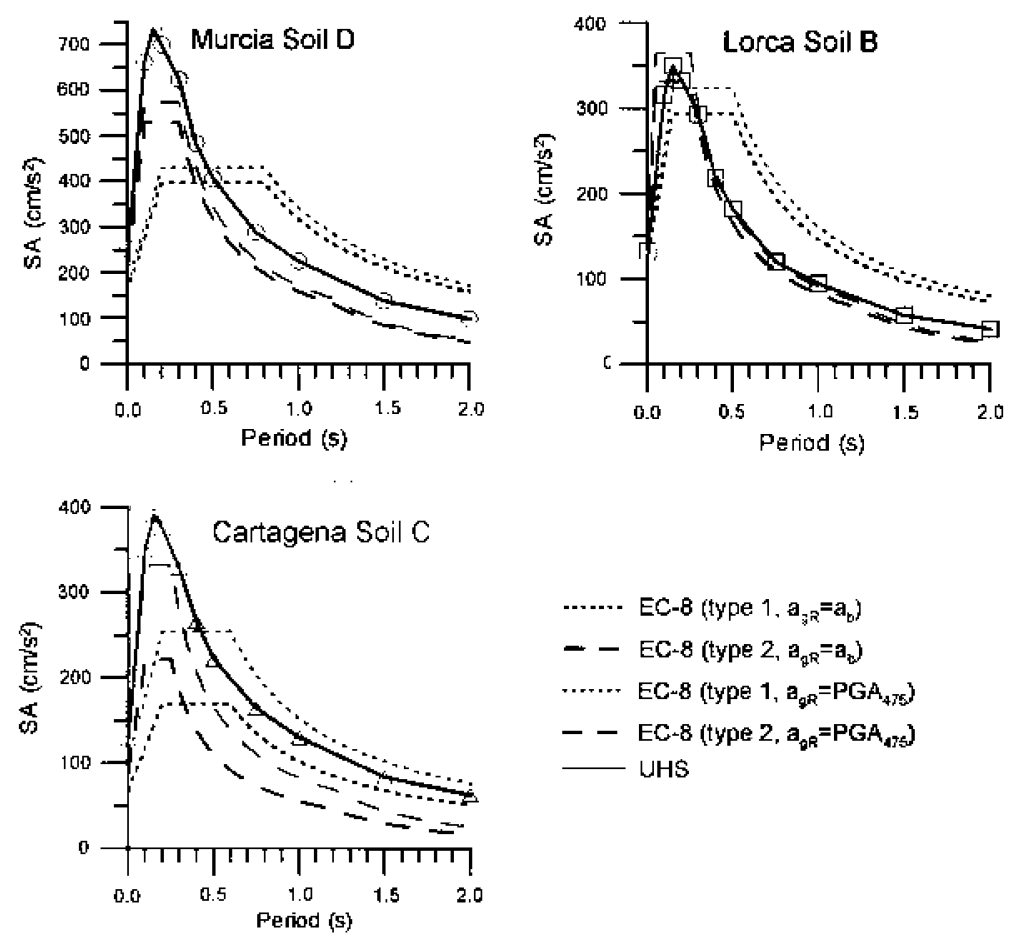

Fig. 7 UHS and EC8 (types 1 and 2) response spectra at Murcia City, Lorca and Cartagena for soil conditions. Two $\mathbf{a}_{\mathrm{gR}}$ values are used at each site

is achieved at the cost of knowing the magnitude of earthquakes that contribute most to the seismic hazard defined for the purpose of probabilistic seismic hazard assessment (CEN 2004), information that is not always accessible for end-users.

Provided that the UHS can be approximated by the envelope of two single SRS corresponding to magnitude-distance-epsilon bins with the highest contributions to short- and long-period target motions, respectively, it seems more appropriate to define the code design spectrum by anchoring a spectral shape at two spectral accelerations (for short and long periods, respectively) than by a single acceleration at the lowermost bound of the period domain (e. g., Bommer and Pinho 2006; Karakostas et al. 2007). This possibility is explored following the approach detailed in the 2003-NEHRP Provisions (BSSC 2003), which is implemented, for instance, in the International Building Code (ICC, 2006).

The 2003-NEHRP Provisions use a spectral shape anchored at two spectral accelerations (for short and long-periods that are extracted from hazard maps) and include building importance coefficients and non-linear, period-dependent soil amplification factors (Borcherdt 1994; Dobry et al. 2000). Specifically, the 2003-NEHRP Provisions consider SA $2475(0.2 \mathrm{~s})$ and $\mathrm{SA}_{2475}(1.0 \mathrm{~s})$, the expected spectral accelerations of 0.2 and 1.0 with a $2 \%$ probability of exceedance in 50 years, equivalent to a return period of 2475 years. These groundmotion values are reduced by a factor $2 / 3$ that compensates for excessively large seismic loads in high-seismicity areas and at the same time provides for uniform margins against collapse along areas with rather different seismic activity (Leyendrecker et al. 2000). However, in areas such as the Region of Murcia, seismicity is not that heterogeneous and this 

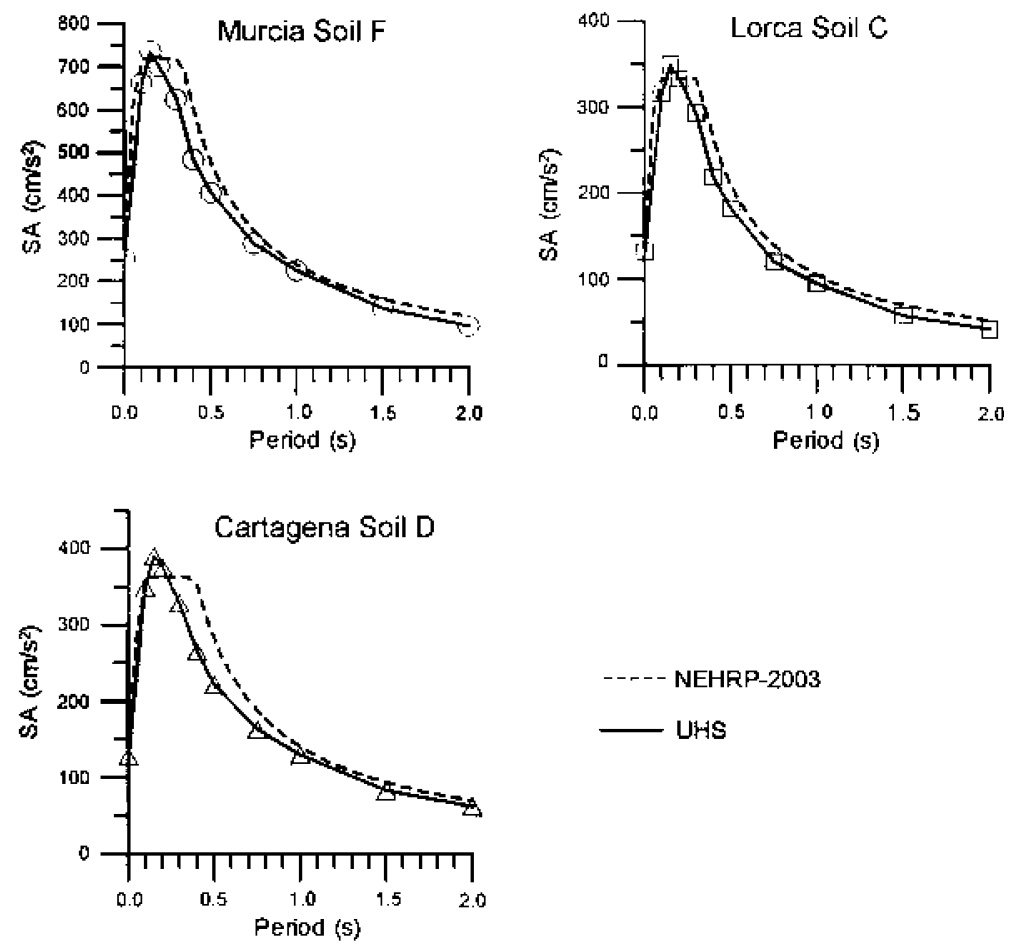

-.-- NEHRP-2003

- UHS

Fig. 8 UHS and response spectra derived following the method included in the NEHRP-2003 Provisions at Murcia City, Lorca and Cartagena for soil conditions

assumption may be overlooked. Consequently, the 475 -year spectral accelerations, $\mathrm{SA}_{475}(0.2 \mathrm{~s})$ and $\mathrm{SA}_{475}(1.0 \mathrm{~s})$ obtained in our work may be directly taken to test the performance of the 2003-NEHRP approach for the sites analysed.

Figure 8 shows the comparison between UHS and 2003-NEHRP spectra considering the acceleration values calculated in the RISMUR PSHA (Table 5) and the amplification factors of the 2003-NEHRP (Table 3). The NEHRP-2003 spectra provide fair approximations to the respective UHS for the three sites considered. Hence, the 2003-NEHRP spectra represent hazard-consistent ground-motion characterisations for the entire period domain at the sites analysed. Given the ground-motion characteristics of the study area (which can be represented by the SRS-envelope), the use of 2003-NEHRP approach as an alternative code spectrum suitable for design of structures regulated by the 475 -year return period is recommended.

\section{Summary and conclusions}

Hazard-consistent response spectra for three relevant sites in the Region of Murcia are presented in this paper. Due to the lack of a complete strong-motion instrumental record in the area, they result very useful for providing a first approach to hazard-consistent groundmotion characterisations at the studied sites, with differing applications depending on the fundamental period of the designed structures. 
Uniform hazard spectra for the 475-year return period are inferred from the results of a PSHA study carried out in the Region of Murcia (Benito et al. 2006a; García-Mayordomo et al. 2007). Maximum ground-motions are obtained in the short-period range (between $0.05-0.40 \mathrm{~s}$, depending on the site).

Hazard deaggregation shows that low-to-moderate $\left(\mathbf{M}_{\mathrm{w}} 4.0\right.$ to 5.5$)$, local ( $\mathbf{R}_{\mathrm{epi}} 0$ to $\left.10 \mathrm{~km}\right)$ events control seismic hazard for PGA and short-period target motions; larger $\left(\mathrm{M}_{\mathrm{W}}>5.5\right)$ and more distant ( $R_{\text {epi }} 10$ to $40 \mathrm{~km}$ ) events control seismic hazard for long-period target motions. The fact that moderate, local events are controlling seismic hazard for target motions corresponding to return periods commonly used in seismic design of conventional structures has strong implications for seismic risk. Firstly, because these moderate-magnitude earthquakes are relatively frequent in the Region of Murcia, as evidenced by the recent, damaging earthquake sequences of 1999 Mula 2002 SW Bullas and 2005 La Paca. Secondly, because the largest part of the Murcian building stock is composed of one to two storey buildings, presumptively with low fundamental periods that coincide with the largest expected ground motions (475-year return period) produced by the magnitude-distance-epsilon bins with higher contribution to total hazard. Hence, although stronger events may occur in the study area, their hazard contribution would be significant for longer return periods and specialimportance structures only.

Besides the UHS, a hazard-consistent ground-motion characterisation of the study area can be obtained from the combination of the specific response spectrum of a small, local earthquake (for short-period ground motions) and the specific response spectrum of a moderate, more distant event (for intermediate-long-period ground motions). Specific magnitude and distance values of such earthquakes are obtained by hazard deaggregation in magnitudedistance-epsilon bins. In the absence of actual strong-motion records corresponding to these magnitudes and distances, the uniform hazard spectra and/or the specific response spectra obtained in this study can be used as guidelines for the definition of hazard-consistent response spectra for design of structures regulated by the 475-year return period.

The comparison of our results with the design spectra provided by current Spanish and European regulations reveals appreciable differences. Only the Eurocode 8 (type 2) response spectrum, anchored with the $\mathrm{PGA}_{475}$ values obtained in this study, reproduces the shape of the hazard-consistent response spectra reasonably well. This result gives an example of the known limitations of using a code spectral shape scaled with a single PGA value and the convenience of considering a spectral shape anchored at representative short- and longperiod spectral accelerations derived from PSHA estimates (e.g., Bommer and Pinho 2006), such as the 2003-NEHRP Provisions. More interestingly, this result shows that EC8 type 2 spectrum (intended for relatively stable regions) is more consistent with the UHS at the 475-year return period derived for the Region of Murcia than EC8 type 1 spectrum (intended for active regions). As the study area is located in the vicinity of an active plate contact, one could expect that the highest hazard contribution comes from stronger earthquakes. However, strong events are relatively rare in south eastern Spain and present a significant hazard contribution for return periods longer than 475 years. EC 8 type 2 response spectrum may result more adequate for design of normal importance structures not only for the study region, but also for other areas of the Mediterranean Basin with similar seismicity. In this context, making the information on hazard-controlling magnitudes to Eurocode 8 end-users available becomes a fundamental issue for its proper implementation.

Acknowledgements The authors thank N. Woollard for the revision of the English version of the paper. They are grateful to Editor in Chief Dr. A. Ansal, whose remarks helped making the paper easier to understand and to two anonymous reviewers whose thorough revisions implied a significant improvement of the paper. 
The RISMUR Project was financed by the Spanish Instituto Geográfico Nacional and Protección Civil de la Región de Murcia. The Spanish Ministerio de Educación y Ciencia partially funded this research (ASPE Project, Reference: CGL2005-07456-C03-03/BTE).

\section{References}

Ambraseys NN, Simpson KA, Bommer JJ (1996) Prediction of horizontal response spectra in Europe, Earthq. Eng Struct Dyn 25:371-400

Ambraseys NN, Douglas J, Sarma SK, Smit PM (2005) Equations for the estimation of strong ground motions from shallow crustal earthquakes using data from Europe and the Middle East: horizontal peak ground acceleration and spectral acceleration, Bull. Earthq Eng 3:1-53

Bazzurro P, Cornell CA (1999) Disaggregation of seismic hazard. Bull Seismol Soc Am 89:501-520

Benito MB, Gaspar-Escribano JM, García-Mayordomo J, Jiménez Peña ME, García Rodríguez MJ (2006a) Seismic Risk in the Region of Murcia. RISMUR Project, vol 1. Seismic hazard evaluation, Madrid (in Spanish)

Benito MB, Jiménez Peña ME, García Rodríguez MJ, Gaspar-Escribano JM, García-Mayordomo J (2006b) Seismic Risk in the Region of Murcia. RISMUR Project, vol 5: Seismic risk evaluation, Madrid (in Spanish)

Benito B, Capote B, Murphy P, Gaspar-Escribano JM, Martínez-Díaz JJ, Tsige M, Stich D, García-Mayordomo J, García MJ, Jiménez ME, Insua-Arévalo JM, Álvarez-Gómez JA, Canora C (2007) An overview of the damaging and low magnitude La Paca earthquake (Mw 4.8) on January 29th, 2005. Context; seismotectonics; and seismic risk implications for South East Spain. Bull Seismol Soc Am 97:671-690

Berge-Thierry C, Cotton F, Scotti O, Griot-Pommera D-A, Fukushima Y (2003) New empirical response spectral attenuation laws for moderate European earthquakes. J Earthq Eng 7:193-222

Bommer JJ, Pinho R (2006) Adapting earthquake actions in Eurocode 8 for performance-based seismic design. Earthquake Engng Struct Dyn 35:39-55

Bommer JJ, Scott SG, Sarma SK (2000) Hazard-consistent earthquake scenarios. Soil Dyn Earthquake Eng $19: 219-231$

Bommer JJ, Scherbaum F, Bungum H, Cotton F, Sabetta F, Abrahamson NA (2005) On the use of logic trees for ground-motion prediction equations in seismic-hazard analysis. Bull Seismol Soc Am 95:377-389

Borcherdt RD (1994) Estimates of site-dependent response spectra for design (methodology and justification). Earthq Spectra 10:617-673

Buforn E, Sanzde Galdeano C(2001) Focal mechanism of Mula (Murcia, Spain) earthquake of 2 February 1999. J Seismol 5:277-280

Buforn E, Cesca S, Goded T, Fresno C, del Muñoz D (2006) The Bullas (Murcia, SE Spain) earthquake, 29 January 2005. J Seismol 10:65-72

Buforn E, Benito B, Sanzde Galdeano C, Fresno C, del Muñoz D, Rodríguez I (2005) Study of the damaging earthquakes of 1911, 1999, and 2002 in the Murcia, Southeastern Spain region: seismotectonic and seismic-risk implications. Bull Seismol Soc Am 95:549-567

Building Seismic Safety Council (BSSC) (2003) NEHRP Recommended Provisions for Seismic Regulations for New Buildings and Other Structures. Part 1: Provisions (FEMA 450), Building Seismic Safety Council of the National Institute of Building Sciences, Washington, D.C., $340 \mathrm{pp}$

Comité Européen de Normalisation (CEN) (2004) Eurocode 8: design of structures for earthquake resistance. Part 1: general rules, seismic actions and rules for buildings. EN 1998-1, Brussels

Dirección General de Protección Civil (DGPC) (2006). Civil Protection Special Plan for Seismic Risk at the Region of Murcia (SISMIMUR). Dirección General de Protección Civil, Consejería de Presidencia, Comunidad Autónoma de la Región de Murcia, Murcia (in Spanish)

Dobry R, Borcherdt RD, Crouse CB, Idriss IM, Joyner WB, Martin GR, Power MS, Rinne EE, Seed RB (2000) New site coefficients and site classification system used in recent building seismic code provisions. Earthq Spectra 16:41-68

Douglas J, Bungum H, Scherbaum F (2006) Ground-motion prediction equations for southern Spain and southern Norway obtained using the composite model perspective. J Earthq Eng 10:33-72

García-Mayordomo J, (2005) Seismic hazard characterization and analysis in Southeast Spain, PhD Thesis, Universidad Complutense de Madrid, Madrid (in Spanish)

García-Mayordomo J, Faccioli E, Paolucci P (2004) Comparative study of the seismic hazard assessments in European national seismic codes. Bull Earthq Eng 2:51-73

García-Mayordomo J, Gaspar-Escribano JM, Benito B (2007) Seismic hazard assessment of the Province of Murcia (SE Spain): analysis of source contribution to hazard. J Seismol (in press) 
Gaspar-Escribano JM, Benito B (2007) Ground motion characterization of low-to-moderate seismicity zones and implications for seismic design: lessons from recent, $\mathrm{M}_{\mathrm{W}} \sim 4.8$, damaging earthquakes in Southeast Spain. Bull Seismol Soc Am 97:531-544

Gaspar-Escribano JM, Murphy P, Benito B (2005) Study of ground motions and damage trends in different building types caused by recent low-magnitude earthquakes in SE Spain. Lessons for defining seismic design criteria. Proceedings 250 th Anniversary of the 1755 Lisbon Earthquake, Lisbon, 1-4 November 2005

Ground Motion Characterization and Benito B, Gaspar-Escribano JM (2007) Seismic hazard assessment in Spain: context, problems and recent developments. J Seismol (in press)

International Code Council (ICC) (2006) International Building Code, 2006 Edition. Falls Church, VA, $631 \mathrm{pp}$

Karakostas CZ, Athanassiadou CJ, Kappos AJ, Lekidis VA (2007) Site-dependent design spectra and strength modification factors, based on records from Greece. Soil Dyn Earthq Eng 27:1012-1027

Leyendrecker EV, Hunt RJ, Frankel AD, Rukstales KS (2000) Development of maximum considered earthquake ground motion maps. Earthq Spectra 16:21-40

López Casado C, Sanzde Galdeano C, Delgado J, Peinado MA (1995) The parameter b in the Betic Cordillera, the Rif and neighbouring areas. Its Relations with the Tectonics of the Region. Tectonophysics 248:277-292

Mancilla FL, Ammon C, Herrmann RB, Morales J (2002) Faulting parameters of the 1999 Mula earthquake, Southeastern Spain. Tectonophysiscs 354:139-155

Martínez-Díaz JJ, Rigo A, Louis L, Capote R, Hernández-Enrile JL, Carreño E, Tsige M (2002) Geological and seismotectonic characterization of the Mula earthquake (February 1999, Mb: 4,8) by means of geological, seismological and RADAR interferometry (INSAR) data. Boletín Geológico y Minero 113:23-33 (in Spanish)

Murphy P (1999) Earthquake in the River Mula region, February 21999 . Study of damage to buildings. Física de la Tierra 11:253-267, (in Spanish)

Norma de Construcción Sismorresistente Española (NCSE-02) (2002). Earthquake-resistant Building Norm, Real Decreto 997/2002, de 27 de septiembre, por el que se aprueba la norma de construcción sismorresistente: parte general y edificación (NCSR-02). Boletín Oficial del Estado 244:35898-35967 (in Spanish)

Pousse G, Berge-Thierry C, Bonilla LF, Bard P-Y (2005) Eurocode 8 design response spectra evaluation using the K-Net Japanese database. J Earthq Eng 9:547-574

Sabetta F, Pugliese A (1996) Estimation of response spectra and simulation of nonstationary earthquake ground motions. Bull Seismol Soc Am 86:337-352

Sabetta F, Lucantoni A, Bungum H, Bommer JJ (2005) Sensitivity of PSHA results to ground motion prediction relations and logic-tree weights. Soil Dyn Earthq Eng 25:317-329

Tsige Aga M, García Flórez I (2006) Proposal of geotechnical "site effect" (seismic amplification) classification of geological formations in the Region of Murcia. Geogaceta 40:39-42 (in Spanish) 